\title{
Anemia in the Elderly: Frequency and Etiologies at University Hospital Center of Point G
}

\author{
Sy Djibril1* ${ }^{*}$ Traoré Abdel Kader1, Kaya Assétou Soukho1, Traoré Djenebou', \\ Gozo Jean-Jonathan Cocou' ${ }^{1}$, Keïta Zakaria ${ }^{2}$, Dembelé Ibrahima Amadou1, \\ Cissoko Mamadou${ }^{1}$, Keïta Kaly ${ }^{1}$, Sangaré Barry Boubacar ${ }^{1}$, Mallé Mamadou', \\ Sy Seydou³, Dembélé Mamadou1, Traoré Hamar Alassane1
}

\footnotetext{
${ }^{1}$ Department of Internal Medicine of University Hospital Center of Point G, Bamako, Mali

${ }^{2}$ General Secretary of the Association "Rabies in West Africa-Mali", Bamako, Mali

${ }^{3}$ Department of Nephrology of University Hospital Center of Point G, Bamako, Mali

Email: *djibroul@yahoo.fr
}

How to cite this paper: Djibril, S., Kader, T.A., Soukho, K.A., Djenebou, T., Cocou, G.J.J., Zakaria, K., Amadou, D.I., Mamadou, C., Kaly, K., Boubacar, S.B., Mamadou, M., Seydou, S., Mamadou, D. and Alassane, T.H. (2019) Anemia in the Elderly: Frequency and Etiologies at University Hospital Center of Point G. Open Journal of Clinical Diagnostics, 9, 115-125. https://doi.org/10.4236/ojcd.2019.94008

Received: August 31, 2019

Accepted: November 12, 2019

Published: November 15, 2019

Copyright () 2019 by author(s) and Scientific Research Publishing Inc. This work is licensed under the Creative Commons Attribution International License (CC BY 4.0).

http://creativecommons.org/licenses/by/4.0/

\section{(c) (i) Open Access}

\begin{abstract}
Introduction: Older people are exposed to particular health problems that must be taken into account, including anemia defined by the World Health Organization (WHO) in people aged 65 and over hemoglobin $<13 \mathrm{~g} / \mathrm{dl}$ in men and $<12 \mathrm{~g} / \mathrm{dl}$ in women. Objectives: To determine the frequency of anemia, to describe its clinical and paraclinical aspects, and to determine the etiologies. Material and Methods: We conducted a cross-sectional study with prospective data collection that took place in the Department of Internal Medicine of the Point G CHU in Mali from January $1^{\text {st }}, 2018$ to August $31^{\text {st }}$, 2018, covering all elderly patients. At least 65 years old hospitalized and/or having consulted and presenting with anemia. Anemia was defined as $\mathrm{Hb}<$ $13 \mathrm{~g} / \mathrm{dl}$ in men and $<12 \mathrm{~g} / \mathrm{dl}$ in women (WHO definition). Biological markers were collected at admission. Results: Anemia was observed in 42 patients in 160 elderly patients, a prevalence of $26 \%$, the age of our patients ranged from 65 to 90 years. The sex ratio was 1.33 . Fifty percent (50\%) of the patients had high blood pressure as antecedents. Weight loss was found in $69 \%$ of cases; $47.6 \%$ of patients had dyspnea on admission. Tachycardia was the physical sign associated with anemia present in $85.7 \%$ of them. The mean hemoglobin level was $9.2 \mathrm{~g} / \mathrm{dl} \pm 2.03$ : thus $50 \%$ of the subjects had microcytic and or hypochromic anemia. The etiologies found were infectious in $31.0 \%$ of cases, inflammatory in $31.0 \%$ of cases, renal in $14.2 \%$ of cases. Chronic hemorrhage, acute haemorrhage, hemolysis accounted for $2.4 \%$ each. We observed $9.5 \%$ of unexplained causes. Conclusion: The frequency of anemia is high. Nearly half of the geriatric population has anemia. The lack of means and the nonperformance of the technical platform to perform all examinations in the eti-
\end{abstract}


ological research of anemia have a significant impact on the rate of unexplained anemias.

\section{Keywords}

Anemia, Elderly, Internal Medicine, CHU Point G

\section{Introduction}

Seniors are exposed to particular physical and mental health issues that need to be addressed [1]. Anemia is one of these conditions [2]. According to the World Health Organization (WHO), the concentration of hemoglobin $(\mathrm{Hb})$ that defines the presence of anemia in the elderly would be $<13 \mathrm{~g} / \mathrm{dl}$ in men and $<12 \mathrm{~g} / \mathrm{dl}$ in women [3] [4]. With these definitions, between 1993 and 2005, anemia affected $24 \%$ of the elderly in the world (164 million people), but with significant regional differences [5].

In Belgium, an older study (in 1976) already reported a prevalence of $35.1 \%$ of anemia in the elderly with an age $\geq 65$ years [6]. These studies show that anemia is not only a public health problem but also a plague at the heart of geriatrics.

In Africa, anemia is frequent. Specifically in Mali, a previous study in 1980 indicated an anemia prevalence of $9.1 \%$ in subjects aged 60 and over [7], while another in 2015 reported an $86.3 \%$ anemia rate in subjects aged 65 years and older [8]. This could be explained by the lifestyle and nutrition changes that have occurred over the years.

Anemia is a common condition in people over 65 years of age with an estimated prevalence of $11 \%$ in men and $10.2 \%$ in women [9]. Contrary to certain beliefs, senile anemia does not exist and must not be neglected in an elderly person [10]. Under each anemia lies a probable etiology, $30 \%$ of cases of anemia are classified unexplained due to lack of sufficient exploration.

Even though the prevalence of anemia in adult subjects, in general, has been studied a lot in Mali, its frequency and etiologies compared with the age group of 65 years and over have been less studied, hence the interest of our study.

\section{Patients and Method}

We conducted a cross-sectional study with prospective data collection spanning the period from January 1, 2018 to August 31, 2018. Our study population included patients aged 65 years and older. All patients were aged 65 years and over, of both sexes, have a hemoglobin level $<13 \mathrm{~g} / \mathrm{dl}$ in men and $<12 \mathrm{~g} / \mathrm{dl}$ in women.

We consulted the registers and all the files of patients who were hospitalized and/or seen externally in the Internal Medicine department in order to gather additional information as needed. Clinical evaluation data, additional examinations and the selected diagnosis(s) were mentioned as variables measured on a 
pre-established standardized individual survey form with socio-demographic sections; anamnestic data; physical examinations; biological examinations.

Data entry was done with the 2013 Office Pack and its data analysis with SPSS 22.0 for Windows. Fisher's exact test was the statistical test used with a risk $\alpha=0.05$.

\section{Results}

From January 1, 2018 to August 31, 2018, 160 people aged 65 and over were hospitalized and or seen in the outpatient department of internal medicine at the University Hospital Center of Point G. Among these patients, we found 42 cases of anemia which gave a prevalence of $26 \%$. Men accounted for $57.1 \%$ of cases with a sex ratio of 1.33 . Mean age was $72.14 \pm 7.67$ with extremes at 65 and 90 years (Table 1).

Among the antecedents, high blood pressure was found in 21 patients slimming was the general sign present in $69.0 \%$ of cases, breathlessness in $47.6 \%$ and tachycardia in $85.7 \%$ (Table 2).

More than one third (38.1\%) of patients had a hemoglobin between 8.1 to 10 $\mathrm{g} / \mathrm{dl}$ with a mean of $9.2 \pm 2.03 \mathrm{~g} / \mathrm{dl}$.

The Mean Corpuscular Volume (MCV) less than $80 \mathrm{fl}$ was found in $50.0 \%$ of cases, the mean corpuscular hemoglobin concentration was less than $33 \mathrm{~g} / \mathrm{dl}$ in $66.7 \%$ and the reticulocyte level was less than $120 \times 10^{3} / \mathrm{mm}^{3}$ in $61.9 \%$ (Table 3).

Microcytic and or hypochromic anemia was found in $50.0 \%$ of patients (Table 2).

A CRP $>5 \mathrm{mg} / \mathrm{l}$ was found in $59.5 \%$ of the cases. Forty-seven point six percent $(47.6 \%)$ of patients had a glomerular filtration rate greater (GFR) than 100 $\mathrm{ml} / \mathrm{min} / 1.73 \mathrm{~m}^{2}$.

At the digestive fibroscopy (esophagus, gastric and duodenal), high digestive bleeding was estimated for 7.1\%; four cases of erythematous gastritis, two cases for both antral ulcer and esophageal varices and one case for each of the following abnormalities: erosive arthritis, gastroesophageal invagination and the antral tumor.

The main etiologies were infectious, neoplastic and systemic, 31.0\% respectively $(\mathrm{n}=13)$, and related to chronic renal failure $14.2 \%(\mathrm{n}=6)$. Anemia of unexplained causes was found in $9.5 \%$ (Table 3 ).

There is a significant statistical link between the type of anemia and the nature of the etiology $(\mathrm{p}=0.0048)$ (Figure 1$)$.

\section{Comments}

\subsection{Limitations of the Study}

Anemia was only explored in 42 patients, which gives us a rough idea of the etiologies. In addition to small data, the early death of patients, the exit of patients against medical advice and the lack of financial means to carry out biological explorations have limited a total view of all patients' medical characteristics.

\subsection{Frequency}

Over a period of 8 months among 160 patients aged 65 and over hospitalized 
Table 1. Distribution by socio-demographic data of antecedents and signs.

\begin{tabular}{|c|c|c|}
\hline Gender & Effective & $\%$ \\
\hline Male & 24 & 57.1 \\
\hline Female & 18 & 42.9 \\
\hline \multicolumn{3}{|l|}{ Age Group (years) } \\
\hline $65-74$ & 30 & 71.4 \\
\hline $75-84$ & 7 & 16.7 \\
\hline$\geq 85$ & 5 & 11.9 \\
\hline \multicolumn{3}{|l|}{ Antecedents } \\
\hline Hypertension & 21 & 50 \\
\hline Diabetes & 7 & 17 \\
\hline Gastroduodenal ulcer & 10 & 24 \\
\hline Viral hepatitis & 4 & 10 \\
\hline Renal failure & 1 & 2 \\
\hline HIV infection & 1 & 2 \\
\hline Other & 8 & 19 \\
\hline \multicolumn{3}{|l|}{ General Signs } \\
\hline Anorexia & 20 & 47.6 \\
\hline Emaciation & 29 & 69 \\
\hline Asthenia & 27 & 64.3 \\
\hline \multicolumn{3}{|l|}{ Functional Signs } \\
\hline Dizziness & 6 & 14.3 \\
\hline faintness & 1 & 2.4 \\
\hline Fall & 1 & 2.4 \\
\hline shortness & 20 & 47.6 \\
\hline palpitations & 15 & 35.3 \\
\hline \multicolumn{3}{|l|}{ Physical Signs } \\
\hline Pallor & 38 & 90.6 \\
\hline Polypnoea & 33 & 78.6 \\
\hline Tachycardia & 36 & 85.7 \\
\hline hypotension & 18 & 42.9 \\
\hline Heart murmur & 4 & 9.3 \\
\hline
\end{tabular}

Table 2. Distribution according to erythrocyte constancy and type of anemia $(\mathrm{n}=42)$.

\begin{tabular}{ccc}
\hline Hb level $(\mathrm{g} / \mathrm{dl})$ & Effective & $\%$ \\
\hline$\leq 6$ & 4 & 9.5 \\
$6.1-8.0$ & 7 & 16.7 \\
$8.1-10$ & 16 & 38.1 \\
\hline
\end{tabular}




\section{Continued}

\begin{tabular}{ccc}
\hline$>10$ & 15 & 35.7 \\
VGM (fl.) & 21 & 50.0 \\
$<80$ & 19 & 45.2 \\
$80-100$ & 2 & 4.8 \\
$>100$ & & \\
CCMH (g/dL) & 28 & 66.7 \\
$<33$ & 14 & 33.3 \\
$\geq 33$ & & \\
Reticulocyte Rate (x10 $3 /$ mm $\left.^{3}\right)$ & 26 & 61.9 \\
$<120$ & 14 & 33.3 \\
not done & 02 & 4.8 \\
Type of Anemia & & \\
Microcytic and/or hypochromic & 21 & 50.0 \\
Regenerative normocytary & 13 & 30.9 \\
Artere generative normocyte & 6.3 \\
Macrocytic & 2 & 14.3 \\
\hline
\end{tabular}

Table 3. Distribution by etiologies.

\begin{tabular}{ccc}
\hline Etiologies & Effective & $\%$ \\
\hline Infectious & 13 & 31.0 \\
Inflammatory (neoplasia and autoimmune disease) & 13 & 31.0 \\
Chronic bleeding & 4 & 9.5 \\
Chronic kidney disease & 6 & 14.2 \\
Acute hemorrhage & 1 & 2.4 \\
Hemolysis & 1 & 2.4 \\
unexplained anemia & 4 & 9.5 \\
Total & 42 & 100.0 \\
\hline
\end{tabular}

$23.7 \%$

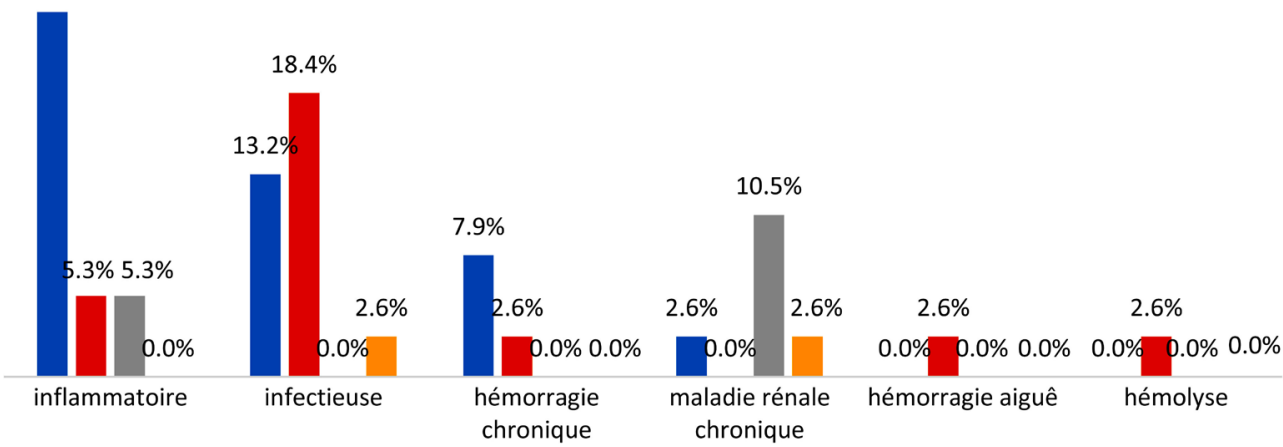

microcytaire et/ou hypochrome normocytaire régénérative n normocytaire arégénérative macrocytaire

Figure 1. Distribution according to the type of anemia and the nature of the etiology found. 
and consulted in the internal medicine department, we included 42 patients according to our criteria, an anemia prevalence of $26 \%$ in the population geriatric.

This result is similar to that of Callera [11] which found $18.6 \%$ in Brazil, but different from those found by Beyne [12] in France with 47\%, Tolo [13] in Mali or $47.73 \%$.

Roth [14] also in France found a frequency of 41\% of anemia as Zulfiqar [15] with a frequency of $47.5 \%$ within the geriatric population.

This difference could be explained by the fact that the studies Beyne [12], Roth [14] and Zulfiqar [15] included a larger number of cases than our study.

\subsection{Age}

The mean age was $72.14 \pm 7.67$ with extremes of 65 and 90 years.

These results are similar to those found in Mali by Tolo [13] and Sandji [8] who found respectively 73.39 years and 73.8 years. But these data are inferior to those found in the West.

Beyne [12], Roth [14] and Zulfiqar [15] respectively reported 85.8; 89.5 and 86.7 years as the average age.

This difference could be explained by the fact that these studies were conducted in countries with a high life expectancy with a relatively aging population.

\subsection{Gender}

Male predominance (57.1\%) was observed in our study with a sex ratio of 1.33; similar predominance to some studies in Mali: 1.71 Tolo [13]; 1.94 Roth [14]; 2.07 Sandji [8]. On the other hand, in several European studies, the predominance is feminine.

Zulfiqar [15] found a sex ratio of 0.58 and Beyne [12], with a sex ratio of 0.52 and Roth [14] with a sex ratio of 0.50 . This difference could be explained to the fact that the proportion of women is higher than that of men in Western populations.

\subsection{Hematological Aspects}

The hemoglobin slice $[8.1-10] \mathrm{g} / \mathrm{dl}$ represented $38.1 \%$ and the mean hemoglobin level was $9.2 \pm 2.03 \mathrm{~g} / \mathrm{dl}$. This result is close to that of Tolo [13] who found an average hemoglobin level of $8.93 \mathrm{~g} / \mathrm{dl}$ in Mali, but lower than those found by other authors as Beyne [12] (10 g/dl); Roth [14] (10.6 g/dl); and Callera [11] $(10.9 \mathrm{~g} / \mathrm{dl})$.

The delay of admission of patients to hospitals could explain these differences of figures because in our countries the use of health care is not systematic, patients wait until the symptoms are more or less troublesome or disabling.

\subsection{Type of Anemia}

Microcytic and/or hypochromic anemia was the most represented type with $50.0 \%$ of cases which is superior to that found by Tolo [13] with a rate of $30 \%$ of microcytic and/or hypochromic anemia. This difference could be explained by 
the variable size of the samples but also by the frequency of the predominant etiologies at the period during which the studies were conducted.

\subsection{Etiologies}

During our study, $9.5 \%$ of cases of anemia were classified as unexplained. These results are superior to those described in the literature.

Tolo [13] reported 6.9\%, Beyne [12] 5\%, and Roth [14], 1\% unexplained anemia.

This difference is explained by the fact that during our study, these cases considered unexplained have not been fully explored due to a lack of financial means. The early death factor is also partly the cause. On the other hand, the efficient technical platforms involved in the etiological research of the anemias in the countries where the studies of Beyne [12] and Roth [14] have been carried out have allowed to find an etiology in the majority of cases.

\section{Conclusions}

The frequency of anemia is high, one quarter (26\%) of the geriatric population has anemia. Very usually it is manifested by shortness of breath and palpitations. There is no senile anemia. The most represented type is microcytic or hypochromic anemia.

A simple etiological assessment makes it possible to find an etiology in $90.5 \%$ of cases; the etiologies are multiple, most often it is of inflammatory origin.

The lack of financial means and the technical platform for the etiological research of anemia have a significant impact on the rate of unexplained anemias (9.5\% in Mali).

\section{Conflicts of Interest}

The authors declare no conflicts of interest regarding the publication of this paper.

\section{References}

[1] OMS (2017) Santé mentale et vieillissement. WHO. http://www.who.int/mediacentre/factsheets/fs381/fr/

[2] Beghe, C., Ershler, W.B. and Wilson, A. (2004) Prevalence and Outcomes of Anemia in Geriatrics: A Systematic Review of the Literature. The American Journal of Medicine, 116, 3-10. https://doi.org/10.1016/j.amjmed.2003.12.009

[3] WHO (2017) Haemoglobin Concentrations for the Diagnosis of Anaemia and Assessment of Severity. WHO.

http://www.who.int/vmnis/indicators/haemoglobin/en/

[4] Izaks, G.J., Westendorp, R.G. and Knook, D.L. (1999) The Definition of Anemia in Older Persons. The Journal of the American Medical Association, 281, 1714-1717. https://doi.org/10.1001/jama.281.18.1714

[5] Gómez Ramírez, S., RemachaSevilla, Á.F. and Muñoz Gómez, M. (2017) Anaemia in the Elderly. Medicina Clínica, 149, 496-503.

https://doi.org/10.1016/j.medcle.2017.10.027

[6] WHO (2017) Anaemia Data by Country. WHO. 
http://www.who.int/vmnis/database/anaemia/countries/en/

[7] Dembele, O.S. (1980) Etude hématologique et étiologique des anémies en médecine interne à Bamako. Bamako, 13.

[8] Sandji, O. (2015) Evaluation multidimensionnelle du sujet âgé de 65 ans et plus en service de médecine interne du CHU Point G. Bamako, 193.

[9] Netgen (2018) L'anémie du sujet âgé : Une pathologie fréquente à ne pas banaliser. Revue Médicale Suisse.

https://www.revmed.ch/RMS/2010/RMS-270/L-anemie-du-sujet-age-une-pathologi e-frequente-a-ne-pas-banaliser

[10] Levy, C. and Siguret, V. (2007) L'anémie du sujet âgé: Une étiologie peut en cacher une autre! Immuno-analyse \& Biologie Spécialisée, 22, 215-221. https://doi.org/10.1016/j.immbio.2007.07.001

[11] Callera, F., Callera, A.F., da Silva, A.M. and Rosa, E.S. (2015) Prevalence of Anemia in a Sample of Elderly Southeastern Brazilians. Revista Brasileira de Hematologia e Hemoterapia, 37, 43-47. https://doi.org/10.1016/j.bjhh.2014.06.005

[12] Beyne-Ranzy, O., Castex, A., Lapoujade, B., Vellas, B. and Adoue, D. (2007) Anémie du Sujet âgé: Une fréquence élevée et de nombreuses causes associées. La Revue de Médecine Interne, 28, S36-S82. https://doi.org/10.1016/j.revmed.2007.03.059

[13] Tolo, N. (2013) Anémie chez le sujet âgé: étude des aspects épidémiologiques, cliniques et étiologiques dans le service de Médecine Interne du CHU Point G. Mémoire: Med, Bamako.

[14] Roth, S., Obrecht, V., Putetto, M., Miniconi, Z., Chaillou-Opitz, S. and Pesce, A. (2009) Anémies du sujet âgé: Expérience d'un service de gériatrie et recommandations. La Revue de Médecine Interne, 30, S77-S151. https://doi.org/10.1016/j.revmed.2009.03.230

[15] Zulfiqar, A.A., Seng, X.S., Gilibert, A., Kadri, N., Doucet, J. and Andres, E. (2018) Anémie chez le sujet âgé: Etude des liens avec les critères gériatriques. La Revue de Médecine Interne, 39, A245. https://doi.org/10.1016/j.revmed.2018.03.260 


\section{Annex}

Pre-established standardized individual survey form

\section{A-Sociodemographic data}

- Age: years

- Sex: / ....... /

$1=$ Male, 2 = Female

B-Antecedent

- Medical

1. Diabetes: /

$/ 1=$ Yes $2=$ No

2. AVC: $/ \ldots$

3. HTA: /__ $/ 1=$ yes $2=\mathrm{No}$

4. Peptic ulcer / $/ 1=$ Yes 2 = No

5. Sickle cell disease / $/(1=$ yes, $2=$ no $)$

6. Asthma / / $(1=$ yes, $2=$ no $)$

7. HIV / / ( 1 = yes, 2 = no) (

8. Viral hepatitis / $/(1=$ yes, $2=$ no $)$

9. Other

\section{- Surgical}

- Notions of drug intake ( $1=$ yes, $2=$ no) $/$ .../

If yes

Lifestyle: $(1=$ yes, 2 = no $)$

-Alcohol: / _ /

- Tobacco: /__ / if yes: /__ / ( $1 \leq$ to $10 \mathrm{P} / \mathrm{A}, 2=10$ to $20 \mathrm{P} / \mathrm{A}, 3 \geq$ to $20 \mathrm{P} / \mathrm{A})$

- Cardiovascular risk factors: Diabetes: / _ / - HTA: / _ / - Obesity: / _ / - Sedentarity: / _ I

- Other: / __/

- Concept of medication taken: / _ /

\section{C-Signs}

- Functional signs of anemia: /

\section{/}

$1=$ vertigo 2 = lipothymia; $3=$ fall; 4 = headache; $5=$ shortness of breath; $6=$ palpitations

- Physical examination

1. General Exam: $(1=$ yes, $2=$ no $)$

Size (in meters): ............ Weight (in $\mathrm{kg}$ ):

BMI $\left(\mathrm{Kg} / \mathrm{m}^{2}\right)$ : Temperature (in ${ }^{\circ} \mathrm{C}$ )

TA (in $\mathrm{mmHg}$ ): Pulse $($ pulsations $/$ minute $)=$

Respiratory rate:.... 
Anorexia: / _ / Slimming: / __ / Asthenia: / _ / Chills: / _ /

Sweat: / _ / Cutaneous conjunctivo-mucous paleness: / __ / Icterus: / _ /

Headache: / _ / Vomiting: / _ / Dehydration: / _ / IMO: / _ /

D-Paraclinical examinations

1. Hemogram:

$\mathrm{GR}=\ldots \ldots \ldots \ldots \ldots \ldots \ldots . . \mathrm{Hte}=\ldots \ldots \ldots \ldots \ldots \ldots . \mathrm{Hb}=\ldots \ldots \ldots \ldots \ldots \ldots \ldots . . \mathrm{VGM}=$

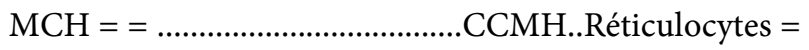

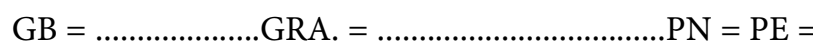

$\mathrm{PB}=\ldots \ldots \ldots \ldots \ldots \ldots . . . . . . . \mathrm{Lym}=\mathrm{M}=$

Toxic granulations $=$

Blastes $=$

Type of anemia: / ______ / 1 _microcytic and/or hypochromic; 2-normocytic

Regenerative; 3-normocytic arterenative; 4-macrocytic)

2. Microcytic anemia

Martial Assessment: (1-increased; 2-normal; 3-lowered; 4-No Done)

Ferritin: / __ / Transferrin: / ___ Serum iron: / __ /; CST: / __ I

Inflammatory status: (1-increased; 2-normal; 3-lowered; 4-No Done)

VS: / __ / CRP: / __ / H

Electrophoresis of $\mathrm{Hb}$ : / ___ / (1-normal; 2-sickle cell disease; 3-thalassemia;

4-No Made)

Endoscopy:

Fibroscopy: / ___ / $(1=$ normal, 2 = bleeding, 3 = other, $4=$ not done $)$

Location bleeding

Other.

Ano-rectoscopy: / ___ / $(1=$ normal, $2=$ bleeding, $3=$ other, $4=$ not done $)$

Location bleeding

Other.

Colonoscopy: / __ / $(1=$ normal, 2 = bleeding, $3=$ other, $4=$ not done $)$

Location bleeding

Other.

Coombs test: / ___ / (1-agglutination, 2-negative)

IDRT / / 1 = negative; $2 \geq 10 ; 3 \geq 15$

Blood culture / __ / $1=$ sterile; $2=$ sepsis. If sepsis: germ

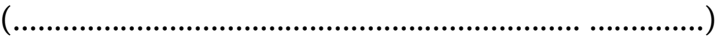

Thick drop / _ _ / 1 = positive; 2 = negative

$\mathrm{ECBU} / \ldots \ldots$ _ $/ 1=$ sterile; $2=$ urinary tract infection

If infection: germ (s)

Leukocytes / ..... / $1 \leq 10,000 / \mathrm{ml} ; 2 \geq 10,000 / \mathrm{ml}$

- Hatiaties / ...... / $1 \leq 5000 / \mathrm{ml} ; 2 \geq 5000 / \mathrm{ml}$

- Antibiogram:

Hormonal balance:

TSHus: FT4: ; TRH:

FT3: 
Folate: / __ / (1-increased; 2-normal; 3-lowered; 4-No Done)

VB12: / _ / (1-increased; 2-normal; 3-lowered; 4-No Done)

G6PD: / __ / (1-increased; 2-normal; 3-lowered; 4-No Done)

Myelogram:

Diagnosis: / / $(1$ = etiology found, 2 = year $)$ 